\title{
O FUNCIONAMENTO DA LINGUAGEM NA ESQUIZOFRENIA: UM ESTUDO LACANIANO
}

Cláudia Maria Generoso

Psicóloga clínica do

Centro Referência

em Saúde Mental/

Cersam (Betim-

MG); mestre em

Psicologia/Estudos

Psicanalíticos, pela

UFMG. Especialista

em Saúde Mental.
RESUMO: Visando caracterizar a especificidade do funcionamento da linguagem na esquizofrenia, serão feitos mapeamento e análise de elementos teórico-clínicos encontrados em textos de Freud e Lacan. O fio condutor dessa investigação se baseará em noções freudianas de 1915 sobre "a palavra como coisa" e a "linguagem de órgão”, bem como a concepção lacaniana de 1954 sobre “o simbólico como real" e a idéia dos anos 1970 sobre a exterioridade do esquizofrênico em relação ao laço social. Tais elementos serão exemplificados com vinhetas clínicas e o relato do esquizofrênico Louis Wolfson.

Palavras-chave: Linguagem na esquizofrenia, psicanálise, clínica.

ABSTRACT: The mechanism of language in schizophrenia: a Lacanian study. In order to characterize what is specific about the way language operates in schizophrenia, mapping and analysis of theoretical-clinical elements found in Freud and Lacan's texts will be carried out. The line of thought in this research will follow Freud's notions from 1915 about "the word as a thing" and the “organ language”, as well as Lacan's conception from 1954 about "the symbolic as real" and the idea from the 1970's about the outer world of the schizophrenic in relation to social bonding. Such elements will be exemplified through clinical vignettes and the report of Louis Wolfson, a schizophrenic.

Keywords: Language in schizophrenia, psychoanalysis, clinic. 


\section{INTRODUÇÃO}

Lacan sempre acentuou a importância de retomar Freud naquilo que ele demonstra ser a essência de sua experiência, que é acompanhar a singularidade dos casos que se apresentavam em sua prática. Ele diz que o "progresso de Freud, sua descoberta, está na maneira de tomar um caso na sua singularidade” (LACAN, 1994, p.21). Foi essa essência que Lacan retirou da experiência freudiana, buscando uma renovação clínica a partir da singularidade dos casos que sofriam os efeitos referentes à sua época. Portanto, na psicanálise, a motivação clínica é fundamental para alimentar uma investigação teórica.

É dentro desse espírito que a importância de trabalhar a psicose, em especial a vertente esquizofrênica, parte de minha experiência clínica, cuja prática se desenvolve em variadas situações: consultório, Centro de Referência em Saúde Mental, moradia protegida, supervisão de acompanhamento terapêutico. A maioria dos casos que utilizam variados dispositivos institucionais de tratamento e outros recursos da saúde mental é composta por pacientes esquizofrênicos. O campo da saúde mental abriga diversos saberes e o risco de esses pacientes serem tomados como objeto de cuidados, pesquisas e ações engessadas em algum ideal é grande, o que poderá reforçar a sua própria posição estrutural de objeto. A imensa fragilidade subjetiva desses pacientes, marcada pela fragmentação da fala e do corpo, pela falta de interesse pelo mundo, passividade etc. permite ações variadas sobre eles: ações de reabilitação psicossocial, pesquisas de medicamentos de última geração, intervenções cognitivo-comportamentais, atendimentos tradicionais em psicanálise etc. Porém, os efeitos de quase todas essas ações muitas vezes não atingem o sujeito ou acabam por reforçar a posição objetal do paciente, permanecendo o isolamento social, a passividade diante do outro, a fragmentação, as esquisitices ou bizarrices, culminando nos casos nomeados de refratários ao tratamento, à medicação, ao convívio social. As intervenções não conseguem atingir o paciente em sua subjetividade, capturá-los para construir soluções que consigam implicá-los. Pelo contrário, ao permanecerem sem interesse pelo mundo externo, esses pacientes acabam sendo rotulados de crônicos ou residuais, rótulos estes que são um atestado para aqueles casos que não têm mais solução.

Pelo fato de meu trabalho com esses pacientes envolver situações diversas e inesperadas, e por ser o mesmo comum dentro do cotidiano de uma casa, na rua, na urgência etc., tais situações podem facilmente gerar intervenções apenas pedagógicas e disciplinares, forçando uma inserção de adaptação social. Diante desse risco, uma investigação psicanalítica lacaniana sobre a esquizofrenia poderá contribuir para a orientação das intervenções. Buscar entender a lógica do funcionamento da linguagem na esquizofrenia possibilita-nos perceber melhor esse modo subjetivo, bem como apostar na construção de soluções que cada um 
indica. Assim, a clínica nos tem ensinado que uma das vias que esses pacientes nos mostram para a construção de soluções é aquela que se desenvolve no 'fazer junto', na ação prática mais ligada ao cotidiano, aos pequenos detalhes da vida, possibilitando uma historicização dos acontecimentos ou incentivando o desempenho de algum papel social possível, bem como a eleição ou construção de algum objeto etc. Como exemplo, cito o caso de um paciente que encontrou o recurso de carregar consigo algum objeto dentro do bolso, desenvolvendo o 'ritual' de tirá-lo do bolso, mostrá-lo a alguém e guardá-lo novamente junto ao seu corpo (cabo de colher, canetas, ímãs etc.). Ele dizia que quando guardava algum objeto no bolso, sua perna parava de doer. Eram objetos descartáveis que ele recolhia do ambiente, usava e jogava fora após encontrar outro. Esse arranjo indica uma forma de tentar concentrar o insuportável do gozo que recai sobre o seu corpo nos objetos destacáveis desse corpo, apontando uma tentativa de separação e delimitação dele.

Esse texto, oriundo de minha dissertação de mestrado, busca circunscrever elementos teórico-clínicos que envolvem a relação da linguagem na esquizofrenia, uma vez que entender o funcionamento da linguagem nessa forma clínica possibilita-nos perceber melhor, nesses casos, a relação estabelecida com o laço social. Referimo-nos aqui à noção de laço social dentro da concepção lacaniana de discurso, tal como desenvolvido nos seminários de Lacan do período 1968-1972. Porém, antes de desenvolver e aprofundar a questão do laço social na psicose foi necessário investigar a especificidade da linguagem na esquizofrenia, pois ela demonstra com mais evidência o que é estar fora do laço social, tornandose uma espécie de 'paradigma' do fora-do-discurso. Portanto, o funcionamento da linguagem na esquizofrenia demonstra especificidades que apontam para outra forma de relação com a linguagem.

Se por um lado podemos colocar a esquizofrenia no centro dos exemplos do que vem a ser o fora do laço social numa perspectiva psicanalítica, por outro lado, observamos que ela não teve um lugar central nos textos de Freud e Lacan, não havendo uma teoria estabelecida sobre esse tipo clínico como há sobre a paranóia. Portanto, nos textos desses autores que mencionam a esquizofrenia podemos circunscrever elementos teóricos que indicam um caminho que esboça uma possível teoria da esquizofrenia.

\section{PERCURSO HISTÓRICO DA ESQUIZOFRENIA}

Privilegiar uma investigação sobre a esquizofrenia é tentar chamá-la ao cenário da psicanálise, lacaniana e freudiana, a um lugar de frente e não apenas àquele lugar mais periférico, tal como podemos perceber nos textos de Freud e de Lacan que a mencionam. Parece-nos que a preocupação desses autores estava em formular instrumentos conceituais diferenciados, próprios à psicanálise, para 
entender a psicose. Uma vez que a esquizofrenia estava mais atrelada à concepção de demenciação e déficit, talvez isso dificultasse ainda mais as elaborações psicanalíticas calcadas na incidência da linguagem e sua relação com o inconsciente na constituição subjetiva. Nesse sentido, a paranóia foi eleita para trabalhar esses instrumentos, assim como podemos perceber que Lacan a ampliou para dar-lhe o estatuto da estrutura mesma da psicose. O termo 'esquizofrenia' sempre foi problemático para Freud e Lacan, porém eles deixaram esta discussão de lado, apesar de utilizarem os fenômenos da esquizofrenia para demonstrar outros conceitos que estavam elaborando.

Considerando essa dificuldade em relação ao termo, bem como o que ele carrega de problemático, iniciamos nossa investigação fazendo um percurso histórico que situa autores importantes na formação dessa entidade clínica. Começamos por Kraepelin que, em 1899, utilizou o 'demência precoce’ para designar essa entidade nosológica. Ele propôs tal denominação numa tentativa de deslocar a referida entidade dos quadros demenciais de origem somática comprovada. Porém, a idéia de que tais casos eram considerados como de evolução demencial, degenerativa, e incuráveis, permaneceu no pensamento kraepeliano, reforçando uma provável origem orgânica.

Em seguida, recorremos ao psiquiatra suíço, da corrente psicodinâmica da escola de Zurique, Eugen Bleuler, que, em 1911, em seu famoso livro Demência precoce: o grupo das esquizofrenias lançou o termo 'esquizofrenia' em substituição à denominada 'demência precoce'. Esse autor demarcou um importante cruzamento do campo da psiquiatria clássica com o campo da psicanálise, em que a influência das idéias de Freud ficam evidentes quando incidem sobre as noções psicopatológicas de afeto e associação. Bleuler, juntamente com Jung, tomou de Freud as noções de libido e de inconsciente, dando importância ao papel da afetividade no funcionamento psíquico. Dessa forma, introduziu a noção de complexo afetivo como fator regulador do modo de funcionamento do pensamento e das ações do sujeito, que, até então, estava atrelado à idéia clássica da associação sobre o funcionamento do pensamento. Para Bleuler, a esquizofrenia referia-se sobretudo à dissociação das funções psíquicas, cujos sintomas fundamentais compreendiam a perturbação das associações do pensamento e da afetividade. Apesar de ser contrário à idéia de Kraepelin sobre a evolução desses casos para a demenciação e incurabilidade, Bleuler não descartou a possibilidade de uma causalidade orgânica.

O termo, então, ganhou maior aceitabilidade e circulação no meio psiquiátrico, e a idéia de dissociação ligada à perda da unidade das funções psíquicas prevaleceu como uma das principais características dessa entidade clínica. Percebemos também a prevalência da idéia de dissociação, relacionada a uma falha na função de síntese do eu, no meio psicanalítico pós-freudiano, bem como na 
psicologia do Eu, cujo tema da esquizofrenia ganhou grande destaque, ao contrário de em Freud e Lacan, os quais privilegiaram a paranóia. A característica da dissociação vinculada à concepção de uma falha na função de síntese do eu estava presente também nas discussões iniciais de Lacan com seus alunos, contidas no Seminário, Livro 1 (1953-1954). Porém, Lacan buscava demarcar uma diferença com relação à concepção da psicologia do Eu. Por este motivo, o presente artigo privilegiou alguns textos do citado Seminário 1, pois foi nesse contexto teórico que surgiram indicações importantes sobre a esquizofrenia, tal como a expressão: “para o esquizofrênico todo o simbólico é real” (LACAN, 1954/1998, p.394), bem como elaborações sobre o imaginário e a constituição do eu, cujos temas são necessários para esclarecer melhor os fenômenos esquizofrênicos.

Diante do contexto teórico aqui mencionado foi necessário fazer uma demarcação de campos, visando a estabelecer o que concernia a Freud e Lacan em relação à esquizofrenia, diferenciando-os de outros contextos. Nessa perspectiva, recorremos ao discípulo de Freud, Paul Federn, teórico da psicologia do Eu, que desenvolveu muitas pesquisas sobre a esquizofrenia. Esse autor referia-se aos fenômenos da esquizofrenia, dentre eles a dissociação, como uma precariedade da unidade das funções do eu nesse tipo clínico que, neste caso, era reconhecida enquanto déficit (FEDERN, 1953/1979). Se, para Federn, na esquizofrenia a tônica era colocada em termos de cisão das funções do eu a partir da perda da unidade das fronteiras do eu, para Freud e Lacan a cisão estava colocada como constitutiva do psiquismo - cisão no sentido da clivagem originária que constitui o psiquismo em consciente e inconsciente. Nesse sentido, o reconhecimento do inconsciente na teoria freudiana e lacaniana é fundamental, ao contrário de Federn, que dava muita importância ao eu enquanto uma unidade de investimento afetivo, coerente e contínuo, em detrimento do inconsciente.

Essa discussão foi importante, pois Lacan buscou deslocar a supremacia do eu, no sentido de uma unidade coerente que ganha maturidade pelo grau de organização, sendo o principal orientador da vida psíquica, para elaborar uma concepção do eu como uma função imaginária. Ele desvincula a idéia de coerência e harmonia do eu, para indicar que há também uma desarmonia no eu, um desconhecimento, tal como na constituição do eu a partir do estádio do espelho, do narcisismo, que leva a uma alienação no $(\mathrm{O})$ utro, pois é a partir da relação com o (O)utro que o eu se constitui. Nesse momento do Seminário 1, Lacan dá ênfase à função do imaginário no sentido de considerar os fenômenos patológicos como uma exacerbação ou um esfacelamento desse registro. Tal como é o caso da paranóia, em que há grande consistência desse registro, prevalecendo apenas a alienação do eu, culminando numa exacerbação do sentido. Ao contrário da esquizofrenia, em que há uma dissolução do imaginário e, por conseguinte, do eu e do corpo. Nesse momento teórico, a libido também é tomada em termos 
imaginários, como uma pregnância do imaginário, tal como ele nomeia de libido imaginária, causadora das perturbações psíquicas. Apesar de desenvolver mais detidamente sua concepção do imaginário, o que de fato estava em foco era a importância do simbólico na estruturação do imaginário, o qual deveria ser regulado pelo simbólico.

\section{ESPECIFICIDADE DA LINGUAGEM NA ESQUIZOFRENIA}

Após um percurso histórico do termo, bem como a intenção de demarcar e circunscrever diferentes campos teóricos em relação à esquizofrenia, buscamos desenvolver neste item elementos teórico-clínicos sobre algumas especificidades do funcionamento da linguagem na esquizofrenia. Mesmo que a apreensão da esquizofrenia em Freud e Lacan se fizesse por elaborações mais periféricas, esses autores deixaram indicações importantes para pensar o modo como opera a linguagem nesses casos. No percurso feito, o qual abrangeu os textos de Freud entre 1911-1917 e, em Lacan, os textos do momento estruturalista de 1954, 1955 e 1958, e ainda um pouco do contexto pós-estruturalista, de 1972-1973, pudemos começar a delimitar o modo de funcionamento da linguagem na esquizofrenia a partir de temas indicados sobre: a palavra como coisa (FREUD, 1915/1976), a linguagem de órgão (FREUD, 1915/1976), o simbólico como real (LACAN, 1954/1998), a exterioridade em relação ao laço social como discurso (LACAN, 1972/2003).

Em Freud, as elaborações sobre os fenômenos esquizofrênicos estão permeadas pela teoria da libido, bem como por sua investigação em relação ao inconsciente, destacando-se o funcionamento da linguagem via modo de satisfação pulsional auto-erótico, observado na linguagem de órgão ou nos fenômenos hipocondríacos. Destaca-se, também, a exterioridade dos mecanismos do inconsciente que se apresentam de forma desvelada, tal como os fenômenos esquizofrênicos que surgem sob a forma da palavra como coisa: manifestação de expressões neológicas, a salada ou copulação das palavras, a concretude da fala que traz um enunciado sem a articulação dos representantes psíquicos com o funcionamento inconsciente, pois não houve o recalque. Como conseqüência disso, há uma prevalência do funcionamento da representação de palavra que não se vincula à representação de coisa como recalcada, não operando o mecanismo da substituição. E, nesse caso, a palavra é tomada como coisa.

Para exemplificar esse funcionamento, trago um fragmento clínico de um paciente que tem o apelido de "boi”. Um dia ele foi ao zoológico, e ao visitar a área de exposição das cobras, escutou alguém ao seu lado comentar que uma jibóia engolia um boi e, neste momento, ele saiu correndo para não ser engolido pela cobra. Nesse caso, a palavra não substitui, pois ele é concretamente a palavra 'boi'. Dessa forma, a linguagem fica mais à deriva, mais vulnerável à decomposição ou ao congelamento, pois aquilo que poderia sustentar ou ancorar 
uma significação e um sentido, não funciona. Verificamos nos textos metapsicológicos freudianos que é a fixação do representante-representação (representante da pulsão que constitui o núcleo do Inconsciente, e o recalque) que cria um ponto de articulação e dá suporte à representação, conferindo-lhe um caráter de realidade, cuja relação entre representação de palavra e representação de coisa serve para designar ou denotar.

Em Lacan, verificamos nos textos do momento estruturalista, que as elaborações referentes à esquizofrenia privilegiaram a alteração na função do imaginário, no sentido de não ser consistente, como aquilo que não foi regulado pelo simbólico. Fazendo uma distinção com a paranóia, cujo simbólico também não é operante, mas há um eu muito consistente, na esquizofrenia não há a sustentação do eu, pois não houve a fixação de uma imagem unificadora, permanecendo aquém da alienação imaginária do eu. Nesse caso, a imagem não fisga o corpo, não cumprindo sua função de estruturação do corpo ao fixar um contorno totalizante. Trata-se da fragmentação do imaginário e, por conseguinte, partes disjuntas do corpo que funcionam sozinhas, não coordenadas pelo simbólico.

No contexto teórico de 1954, em que aparece a expressão o simbólico é real (LACAN, 1954/1998, p.394), Lacan dá ênfase ao registro do imaginário, associando a ele a libido, e, por conseguinte, as perturbações psíquicas, no sentido das flutuações libidinais (LACAN, 1954/1986, p.210). Nessa perspectiva, a expressão acima nos remete a uma falência do imaginário que não foi regulado pelo simbólico. Sendo assim, prevalece o funcionamento da linguagem que não foi envolvida pelo imaginário, pois não há o investimento da libido imaginária - conforme nomeia Lacan nesse momento (LACAN, 1954/1986, p.166). Essa libido é que permitiria certa consistência da linguagem na vertente imaginária. Diante dessa inconsistência imaginária, isso nos sugere uma relação direta da linguagem com o real que não foi separado pelo simbólico, no sentido de poder representálo simbolicamente. Talvez possamos dizer que é nesse nível que se apresenta a dimensão da linguagem não articulada ao apelo, manifestando-se a fala sem a intenção, sem entonação, sendo isso o que faz se prender ou querer algo, pois não há o investimento da libido imaginária. Se não há captura imaginária, podemos dizer que não houve a alienação imaginária, a qual é uma característica dos paranóicos que ficam detidos apenas nessa alienação.

Essa dimensão da linguagem, que não foi investida libidinalmente, é verificada em muitas falas de esquizofrênicos, tal como a desagregação ou descarrilamento do pensamento, as pára-respostas, as expressões sem nexo ou dissociadas, a falta de interesse pelo mundo, as expressões neológicas, as quais não remetem a nada, a nenhuma significação (mesmo que delirante). Podemos dizer que essa dimensão da linguagem é o que levou Bleuler a tratá-la em termos de dissociação do pensamento, cuja consciência não conseguiu cumprir sua função de ligação e orientação das 
associações dirigidas a uma meta principal. Ou Federn, que considerou como uma desadaptação do Eu em sua dimensão de unidade de investimento, incapaz de comandar os processos psíquicos. Podemos dizer que Freud e Lacan (FREUD \& BREUER, 1893-1895/1987 e LACAN, 1960/1998) avançam nesse ponto, quando consideram a importância da cisão do psiquismo como constituinte para qualquer sujeito, não sendo específico da esquizofrenia. Bem como quando eles fazem essa discussão vinculando-a de uma forma de funcionamento diferente do inconsciente, dando ênfase ao inconsciente na articulação da linguagem.

Já nos textos de Lacan, a partir dos anos 1970, a linguagem ganha outro estatuto, pois o simbólico já não tem o lugar de primazia, havendo uma íntima relação entre significante e gozo. Nesse momento, o gozo, que é o correlato da satisfação libidinal freudiana, já não está numa estreita relação com o imaginário, mas sim com o significante e o real. É dentro desse contexto teórico que a indicação da esquizofrenia, no artigo O aturdito (1972), assinala uma posição da mesma como exterior ao laço social a partir da noção de discurso: “...o dito esquizofrênico ao ser apanhado sem a ajuda de nenhum discurso estabelecido” (LACAN, 1972/2003, p.475). O discurso vem cumprir uma função de articulação e arranjo entre a linguagem e o que resta fora dela, encarnado pelo objeto mais-de-gozar, índice do real. Essa função de arranjo, possibilitada pelo discurso, permite lidar melhor com o corpo, criando lugares e funções simbólicas estáveis para os órgãos que compõem uma estrutura de funcionamento unificado e não questionável constantemente. Nessa defesa do real pelo simbólico (MILLER, 1996), a relação do ser falante com a linguagem é de habitá-la e de fazer dela seu instrumento, conforme indica Lacan no artigo $O$ aturdito.

Devido ao fato de o esquizofrênico ser remetido ao fora do discurso, manifesto na conexão imediata entre o significante e o gozo, bem como sofrer dos efeitos da linguagem que o habita, invadindo-o, cuja posição é de instrumento, ele precisa inventar funções para o seu corpo despedaçado. Nesse caso, os órgãos não têm uma função estável, se manifestando à revelia do sujeito, e falam por si, causando as vivências de alteração ou modificação corporal que se apresentam sob a forma de linguagem de órgão, valendo-nos aqui da nomeação de Victor Tausk, discípulo de Freud (TAUSK, 1919/1990). Outro reflexo desse problema do funcionamento da linguagem, sem o amparo do discurso, apresenta-se na ironia infernal do esquizofrênico que se atualiza na ausência do sujeito do laço social como discurso. Isso nos coloca a questão de como poderemos operar, na clínica, a partir do fora-do-discurso. Dizendo de outra forma, como pensar intervenções clínicas que considerem o laço social além da noção de discurso.

A ironia e a linguagem de órgão, as quais podemos associar a um modo de decomposição da linguagem, bem como à satisfação pulsional ou ao gozo deslocalizado que invade o corpo, fragmentando-o, podem ser ilustradas pelo 
relato de Louis Wolfson, contido em seu livro Le schizo et les langues (WOLFSON, 1970). Trata-se de um americano nascido em Nova York, e como ele mesmo se nomeia: "o estudante de línguas esquizofrênico", que não suportava ouvir a língua materna - o inglês. Ele nos mostra como sofre dos efeitos da linguagem que o decompõem, agindo diretamente em seu corpo, pois não serve para ampará-lo, uma vez que ele não habita a linguagem que se apresenta numa outra vertente, tal como veremos a seguir.

Wolfson diz que, desde criança, já apresentava dificuldade para falar, ler e ouvir a língua materna. Essa dificuldade foi associada por seus professores a uma incapacidade intelectual, sendo ele transferido para uma classe de alunos com "retardo mental". Ele mesmo diz que foi uma luta para aprender a língua, conseguindo falá-la em idade já avançada. Isso aconteceu também em relação à leitura convencional, "travando nova batalha”. Era difícil, para ele, manter a atenção, a concentração e o interesse sobre as lições de leitura, uma vez que as achava difíceis de compreender, bem como desinteressantes e sem importância. Essa dificuldade foi acompanhada por tiques nervosos e maus hábitos, os quais ele diz ter desenvolvido desde criança. Sobre essa dificuldade, ele comenta: "Em uma palavra, ele não tinha gostado de ler e sem dúvida porque ele quase não podia fazer isso"1 (WOLFSON, 1970 p.34).

Apesar da dificuldade em aprender a língua no ensino primário, a partir de seus 20 anos de idade ele passou a se interessar de forma "fanática e fantástica" pelo estudo de algumas línguas estrangeiras, apresentando imensa ansiedade em dominá-las - principalmente o francês, o alemão, o hebraico e o russo. Wolfson diz que concluiu o ensino médio e cursou, por quatro anos, a universidade, sendo, nesses estudos, os momentos importantes de contatos com línguas estrangeiras. Isso vem demonstrar que sua dificuldade não se referia a um déficit intelectivo, mas sim à estrutura psicótica que apresentava outra ordem de perturbação concernente à linguagem.

A língua materna era tão insuportável de ouvir, que, constantemente, ele tapava os ouvidos com os dedos para abafar o som. Outro mecanismo que desenvolveu mais tarde foi andar com um estetoscópio no ouvido, unindo a parte inferior desse instrumento a um gravador portátil, para ouvir músicas em línguas estrangeiras. Sobre isso, diz que ele foi o precursor do walkman. Para Wolfson, o difícil era o som da língua, sobretudo o de alguns fonemas, pois o mesmo entrava em seu ouvido e lhe causava dor no corpo, retumbava em seu tímpano: "o espírito era possuído pelas palavras, dominando-o e causando-lhe ataques” (WOLFSON, 1970, p.117-118). Quanto a esses ataques, ele se refere aos

1 Tradução livre de: “En un mot il n'avait pás aimé lire et sans doute parce qu'il n'avait guère pu”. 
momentos em que era "tocado de estupor" pela invasão de palavras ouvidas ou lidas que dominavam seu espírito por um ou vários minutos. Esse estado era mais intensificado quando as palavras eram ditas pela mãe e entravam em seu ouvido, pois a relação com a mãe era muito persecutória e ambivalente. Ele dizia que a mãe queria perturbá-lo, não perdendo a oportunidade de falar-lhe inesperadamente em inglês, demonstrando com isso

"um prazer macabro nessa boa oportunidade de injetar de alguma forma as palavras que saíam da sua boca nas orelhas de seu filho, seu único filho - ou como ela lhe tinha dito varias vezes: sua única posse - , parecendo tão feliz por fazer vibrar o tímpano dessa única posse, e em conseqüência disso, os ossículos do ouvido médio da dita posse, seu filho, em uníssono quase exato com suas cordas vocais..." (WOLFSON, 1970, p.183) ${ }^{2}$

Portanto, não era o sentido que o incomodava, mas o som, o ruído da língua cravado no corpo, apresentado em especial na pronúncia de sua mãe. Isso vem demonstrar como não há uma separação desse Outro materno, cujas palavras lhe invadem, de forma imperativa e caprichosa, sendo a voz da mãe uma extensão do tímpano dele. Observamos, aqui, que não houve o estabelecimento de bordas do corpo, uma hiância que separaria seu corpo da fala da mãe, criando lugares para a linguagem exterior ao corpo.

Diante dessa invasão, Wolfson nos demonstra suas tentativas de construir um procedimento para decompor a língua, tentando tratar a linguagem e construir um corpo, fazendo arranjos cotidianos de conversão lingüística para lidar com a língua materna destrutiva. É justamente no momento de junção da palavra-ruído que Wolfson lança mão do seu procedimento. Tal como indica Foucault, diante da intrusão das palavras que surgem coladas com a hostilidade do alimento da língua materna, dizendo respeito a uma linguagem privada de distância, a qual permitiria designar, Wolfson responde com seu procedimento - ele tapa os orifícios (boca, ouvido, olhos) abertos ao mal que vem da palavra materna, transformando essas palavras-coisas em línguas estrangeiras que o apaziguam. Trata-se de uma tentativa de criar um mínimo de interiorização e exteriorizar uma língua que tomou lugar diretamente em partes de seu corpo: ouvido, boca, olhos, ânus (FOUCAULT, 1970/2001).

\footnotetext{
2 Tradução livre de: “[...] espèce d'une joie macabre par cette bonne opportunité d'injecter en quelque sorte les mots qui sortaient de sa bouche dans les oreilles de son fils, son seul enfant - ou, comme elle lui avait de temps en temps dit, son unique possession -, en semblant si heureuse de faire vibrer le tympan de cette unique possession et par conséquent les osselets de l'oreille moyenne de ladite possession, son fils, en unisson presque exacte avec ses cordes vocales, à elle, et en dépit qu'il en ê̂t".
} 
Diante dessa tragédia em relação à língua, é que Wolfson desenvolve um procedimento com determinadas regras para verter o inglês que ouvia em outros idiomas. Conforme indica Deleuze (1997), o procedimento compreende o seguinte: diante de uma palavra da língua materna (o inglês), ele precisa encontrar uma palavra de outra língua que tenha o sentido similar e também que tenha algumas letras, sons ou fonemas comuns. Trata-se de uma operação de conversão em línguas estrangeiras abrangendo o movimento fonético e o sentido, extraindo de cada conversão regras fonéticas que serão aplicáveis a outras conversões posteriores. Essa conversão teria que acontecer de forma muito rápida, quase simultaneamente à palavra ou frase ouvida ou lida em inglês, operação que se centrava na decomposição dos sons das palavras, compondo outras palavras estrangeiras existentes no código, mas sempre utilizando algumas letras ou sílabas do original. Esse processo remete-nos a um detalhado trabalho artesanal de montagem de palavras, como se da língua natal surgisse, ou engendrasse, outra língua estrangeira.

Geneviève Morel (1986) indica que o fundamento desse procedimento está na mentira contada pelo pai de Wolfson, quando ele era criança, enganando-o ao lhe dizer que a palavra para árvore em russo era a mesma do inglês (tree). A esse engano, ela associa a referência de Lacan, contida no Seminário 3, sobre a noção de significante em sua existência radical, uma vez que "todo verdadeiro significante é, enquanto tal, um significante que não significa nada”, estando aí a distinção em relação à significação (LACAN, 1955-1956/1988, p.212). A esse respeito, Lacan prossegue dizendo que se trata da dimensão do significante no real que serve, não para a informação ou a significação, mas para iludir e enganar, pois não exprime nenhuma relação direta com a ordem da necessidade. $\mathrm{Na}$ psicose, há um impasse na relação do sujeito com o significante, pois há uma perplexidade em relação ao mesmo. Nesse ponto Lacan diz que o problema é que o Outro enquanto detentor do significante está excluído, ocorrendo aí os fenômenos de linguagem, tais como as frases interrompidas, “já que há um uso por assim dizer implicante do significante”. Ou seja, diante da impossibilidade de formular verdadeiramente um enigma que possa amarrar as significações, o que surge é o significante como tal, em estado puro e que não significa nada, mas que só engana. Seguindo essa lógica do significante como tal, ou assemântico, é que Morel associa às decomposições lingüísticas realizadas por Wolfson, constatando que é uma constante atualização desse engano que o leva a transformar sua língua materna, cuja vertente é o significante enquanto tal, utilizado para enganar, de certa forma, o Outro materno.

A manutenção de algumas letras da palavra original em inglês, em suas conversões, era uma maneira de separar algo de material que se apresentava sob a forma ortográfica ou da letra, daquela da significância vinda da mãe, da língua 
materna, possibilitando, com isso, isolar alguma materialidade que pudesse dar suporte para as conversões que incluíam a modificação do som e a manutenção do sentido. Podemos dizer que ele tenta enganar a língua materna, ou a voz da mãe, escamoteando sua pronúncia. Por exemplo, Wolfson modifica a palavra inglesa tree (árvore), decompondo-a, pois o som do t pronunciado nesta palavra o machuca. Ele trabalha com o t e o r para transformá-la em tere, convertendoa foneticamente em dere, a qual faz surgir a palavra russa derevo (árvore). Faz essa conversão porque o som do t associado ao ree, formando a pronúncia [tri:] (conforme o alfabeto internacional de fonética), o irrita e invade seu espírito, impulsionando-o a se livrar desse som. Wolfson fazia longas pesquisas nos dicionários de línguas, sempre recorrendo ao alfabeto internacional de fonética para fazer suas conversões lingüísticas, buscando se apoiar e se servir do código de um contexto mais universal em seu combate às mensagens que se interrompiam ao esbarrar na "palavra como gozo”: aquela que destrói a associação da cadeia significante e, por conseguinte, a unidade corporal se desfaz.

Podemos dizer que Wolfson é um caso exemplar do modo de funcionamento da linguagem na esquizofrenia, bem como a tentativa reiterada de inventar recursos para encontrar uma possível solução de separação do Outro materno.

Os elementos teórico-clínicos referentes à ironia e à linguagem de órgão levaram-nos a inferir que se trata da linguagem em sua vertente da palavra como gozo (MILLER, 1999, p.101). Ou seja, do simbólico como real, mais na dimensão de lalíngua (LACAN, 1972-1973/1985), havendo prevalência do significante como real que se manifesta pela via do não-sentido, interrompendo, assim, a seqüência semântica da cadeia significante. Se na paranóia associamos o modo de funcionamento da linguagem a uma imaginarização do simbólico, ou ao significante como imaginário, em busca de um sentido sem falhas, na esquizofrenia podemos dizer que o significante é real. Isto quer dizer que a tônica está no ruído da palavra, na vertente de lalíngua, cuja finalidade é estar do lado do gozo na apreensão das palavras, e não numa função comunicativa e de sentido. É essa vertente da palavra como gozo que invade o corpo de Wolfson, tal como vimos aqui. Assim, fica mais evidente que, na esquizofrenia, é a constituição de um corpo que está em questão e, por conseguinte, a consistência do imaginário. Essa é uma via importante a ser considerada na condução de uma prática clínica com esquizofrênicos, pois nos coloca várias questões, dentre elas, como operar com a ironia infernal do esquizofrênico que tanto decompõe como é decomposto pela linguagem, sem se fixar a algum significante que possa servir como certa ancoragem?

O contexto teórico do final do ensino de Lacan nos permite pensar que, se a princípio ele privilegiou a paranóia como paradigma da psicose, mais no final de sua obra percebemos que recorre, de certa forma, à esquizofrenia para demonstrar uma outra concepção de linguagem, pensada a partir da dimensão do 
real. Assim, a esquizofrenia testemunha essa relação com o real da linguagem, pois desvela e denuncia a natureza de semblante da linguagem quando ela é recoberta pelo discurso. Como indica Miller, se considerarmos a vertente do real da linguagem, cujo simbólico se torna real, a esquizofrenia pode ser considerada como a medida da psicose (MILLER, 1996).

\section{CONCLUSÃO}

Esta pesquisa nos levou a entender certo funcionamento da linguagem na esquizofrenia, o que nos possibilita intervir em nossa prática de um lugar um pouco mais preciso. Se tomamos a premissa de que são os pacientes que nos mostram por onde deve ir a construção de algum arranjo, ou alguma solução para eles, a partir daí percebemos que, muitas vezes, a solução não se embasa tanto na construção de um sentido. Entretanto, podemos apostar com eles nas pequenas construções que ocorrem fora de qualquer sentido, mas que apaziguam e têm mais efeitos terapêuticos. Tal como uma paciente que, diante da decomposição de seu eu, bem como do seu desdobramento em várias pessoas que invadem seu corpo, comandando o seu agir, ela encontrou um pouco de tranqüilidade no ato de escrever suas decisões e indignações no caderno de recados da moradia protegida onde vive. Quando essa invasão se intensifica mais, ela recorre ao caderno. Talvez isso seja uma tentativa de dar um mínimo de materialidade que possa fixar algo diante de uma linguagem que se pulveriza facilmente, incidindo no corpo de forma a decompô-lo.

Enfim, perceber o modo de funcionamento da linguagem e o que poderá surgir como construção de pequenos arranjos a serem incentivados é o que importa na tentativa de uma investigação sobre a esquizofrenia.

Recebido em 15/6/2007. Aprovado em 11/8/2007.

\section{REFERÊNCIAS}

BERCHERIE, P. (1989) “A psiquiatria moderna: a era psicodinâmica”, in Fundamentos da clínica: história e estrutura do saber psiquiátrico. Rio de Janeiro: Jorge Zahar.

BLEULER, E. (1911/1960) “Introducción general”, in Demencia precoz: el grupo de las esquizofrenias. Buenos Aires: Hormé/Paidós.

(1911/1960) "Sintomatologia”, in Demencia precoz: el grupo de las esquizofrenias. Buenos Aires: Hormé/Paidós. 
DELEUZE, G. (1997) “Louis Wolfson, ou o procedimento”, in Crítica e clínica. São Paulo: Editora 34.

FEDERN, P. (1953/1979) "L'hygiène mentale du moi dans la schizophrénie", in La psychologie du moi et les psychoses. Paris: PUF.

FEDERN, P. (1953/1979) “Le moi dans la schizophrénie”, in: La psychologie du moi et les psychoses, Paris: PUF.

FOUCAULT, M. (1970/2001) "Sete proposições sobre o sétimo anjo", in Estética: literatura e pintura, música e cinema. Rio de Janeiro: Forense Universitária.

FREUD, S. (1976) Edição standard brasileira das obras psicológicas completas. Rio de Janeiro: Imago.

(1893-1895) “Sobre o mecanismo psíquico dos fenômenos histéricos: comunicação preliminar e considerações teóricas”, v. II, p.39-250.

(1914) “Sobre o narcisismo: uma introdução”, v. XIV, p.85-119.

(1915) “O recalque”, v. XIV, p.165-182.

(1915) “O inconsciente”, v. XIV, p.185-245.

([1915] 1917) "Suplemento metapsicológico à teoria dos sonhos", v. XIV, p.249-267.

FREUD, S. \& BREUER, J. (1893-1895/1987). "Estudos sobre a histeria”, in Edição standard brasileira das obras psicológicas completas. Rio de Janeiro: Imago, v. II.

KRAEPELIN, E. (1999) "A demência precoce, sinais gerais da doença, formas paranóides”, in ALBERTI, S. (org.). Autismo e esquizofrenia na clínica da esquize. Rio de Janeiro: Marca d’Água.

LACAN, J. (1953-1954/1986) O seminário livro 1, Os escritos técnicos de Freud. Rio de Janeiro: Jorge Zahar.

(1954/1998) "Resposta ao comentário de Jean Hyppolite sobre a Verneinung de Freud”, in Escritos. Rio de Janeiro: Jorge Zahar Editor. (1955-1956/1988) O seminário livro 3, As psicoses, Rio de Janeiro: Jorge Zahar.

(1960/1998) "Observações sobre o relatório de Daniel Lagache: psicanálise e estrutura da personalidade”, in Escritos. Rio de Janeiro: Jorge Zahar Editor.

(1969-1970/1992) O seminário livro 17, O avesso da psicanálise. Rio de Janeiro: Jorge Zahar.

(1972/2003) “O aturdito”, in Outros escritos. Rio de Janeiro: Jorge Zahar.

(1972-1973/1985) O seminário livro 20, Mais, ainda. Rio de Janeiro: Jorge Zahar.

MALEVAL, J.-C. (1996) "Delocalisation de la jouissance et perplexité angoissée (Po)”, in Logique du delire. Paris: Masson.

MILLER, J.-A. (1981) “Esquizofrenia y paranóia”, in Psicosis y psicoanalisis: quehacer del psicoanalista. Buenos Aires: Manantial. Zahar.

(1996) “A clínica irônica”, in Matemas I. Rio de Janeiro: Jorge

(2000) Os seis paradigmas do gozo. Op̧̧ão lacaniana, n.26/27. São Paulo: Eólia, p.87-105. 
MOREL, G. (1986) Point final à une planète infernale. Ornicar? Revue du champ freudien, n. 36, La logique de la suspicion, jan-mar. Paris: Navarin Editeur, p.82-93.

TAUSK, V. (1919/1990) "Da gênese do aparelho de influenciar no curso da esquizofrenia”, in BIRMAN, J. (org.) Tausk e o aparelho de influenciar na psicose. São Paulo: Escuta.

WOLFSON, L. (1984) Le schizo et les langues ou la phonétique chez lê psychotique (esquisses d'um étudiant de langues schizophrénique). Paris: Gallimard.

Cláudia Maria Generoso

claudiageneroso@bol.com.br 